\title{
Mental health stigma in a multicultural society: the case of Israel
}

\author{
Ora Nakash $^{1^{*}}$ and Itzhak Levav ${ }^{2}$ \\ ${ }^{I}$ Interdisciplinary Center (IDC), Herzliya, Israel ${ }^{2}$ Haifa University, Israel. \\ (Received September 1, 2012; Accepted September 26, 2012)
}

\begin{abstract}
The paper reviews the available information on the stigma associated with mental health in a multicultural society such as that of Israel, where as usually, no group of the population is free of this complex and ubiquitous social phenomenon.

To try to understand the process is reviewed the available scientific literature on the prevalence of stigma in mental health in different population sectors, putting it in relation with the knowledge that social psychology offers on social mechanisms of production and perpetuation of the stigma.

Finally suggests some directions to face the heavy burden of stigma in people with mental illness.
\end{abstract}

Keywords: stigma, mental illness, multicultural society.

\section{Salud Mental en una sociedad multicultural: el caso de Israel}

RESUMEN: El artículo revisa la información disponible sobre el estigma relacionado con problemas de salud mental en una sociedad multicultural como es la de Israel, en la que como sucede habitualmente, ningún grupo de la población está libre de este complejo y ubicuo fenómeno social.

Para intentar entender el proceso se revisa la literatura científica disponible sobre prevalencia del estigma en salud mental en distintos sectores poblacionales, poniéndola en relación con los conocimientos que la psicología social ofrece sobre los mecanismos sociales de producción y perpetuación del estigma.

Finalmente se sugieren algunas direcciones para enfrentar la pesada carga del estigma en las personas con enfermedad mental.

Palabras clave: estigma, enfermedad mental, sociedad multicultural.

Stigma refers to severe social disapproval of personal characteristics, beliefs or behaviors that are perceived to be deviant from cultural norms. The term originates from ancient Greece, denoting a physical brand or mark applied to social outcasts (e.g., slaves, traitors) to indicate socially devalued status (Goffman, 1963). Stigma involves stereotypes, referring to cognitive labels that characterize members of devalued groups, and prejudice, the negatively-toned affect directed toward those individuals. Ultimately, stigma leads to discrimination, thus limiting the exercise of human rights of those in disadvantaged groups and their access to life opportunities as codified in the International Covenant on Economic, Social and Cultural Rights (1976). Importantly, stigma has the potential for internalization of the degraded status by those who are stigmatized-i.e., self- 
stigma (Brohan, Elgie, Sartorius \& Thornicroft, 2010; Corrigan, Watson \& Barr, 2006; Lysaker, Tsai, Yanos \& Roe, 2008; Struch et al., 2008).

Stigma against mental illness is ubiquitous (Institute of Medicine, 2002; Link, Phelan, Bresnahan, Stueve \& Pescosolido, 1999; Livingston \& Boyd, 2010). For example, more than two thirds of the US public view persons with mental illness as dangerous (Link, Phelan, Bresnahan, Stueve \& Pescosolido, 1999), while approximately $70 \%$ of respondents in a survey in Germany shared the view that 'former mental patients' are disadvantaged when it comes to applying for a job or dating (Angermeyer \& Matschinger, 2003). A similar proportion of mental health professionals surveyed in Switzerland favored revoking drivers' licenses of persons with mental disorders (Norft, Rössler \& Lauber, 2006).

Stigma is associated with health-seeking behavior, such as treatment lag and gap, poorer psychological adjustment and poorer treatment adherence, course and outcome (Angermeyer \& Matschinger, 2003; Hinshaw \& Stier, 2008; Institute of Medine, 2002; Tal, Roe \& Corrigan, 2007). Stigma is a significant barrier to service-users' access to knowledgeable healthcare, it may abort treatment, deplete social resources, and limit opportunities for recovery (Kadri \& Sartorius, 2005). Stigma frequently generates feelings of shame, guilt, low self-esteem, social dependence, isolation and hopelessness (Kadri \& Sartorius, 2005) (Kadri \& Sartorius, 2005; Rüsch, Lieb, Bohus \& Corrigan, 2006).

In this article we review literature on mental illness stigma in Israel. As in other societies, no population group, of the many that are part of this cultural mosaic, is free from stigma. To better understand its dynamics and characteristics, we start by reviewing briefly the mechanisms rooted in social psychology that underlie the formation and perpetuation of stigma world-wide and we continue by reviewing the literature on the local prevalence of mental health stigma and its consequences. Finally, we suggest future direction in addressing the hidden burden of stigma on persons with mental illness.

\section{SOCIAL MECHANISMS AT THE BASIS OF STIGMA}

Social categorization and associated psychological processes play a critical role in the formation and perpetuation of stigma and intergroup biases. One important aspect of the social categorization process (Allport, 1954) involves a distinction between the group containing the self (the ingroup) and other groups (the outgroups) - between the "we's" ("healthy") and the "they's" ("the mentally ill") (see social identity theory (Tajfel \& Turner, 1979); self-categorization theory (Turner, Hogg, Oakes, Reicher \& Wetherell, 1987). A number of mechanisms accompany the strong tendency for humans to identify with ingroups readilly and, often, automatically (Tajfel \& Turner, 1979) as they serve as efficient mental shortcuts in processing information from the social environment (Corrigan $\&$ Watson, 2002). These mechanisms include stereotyping and related socialcognitive processes that accentuate the individual identities and positive traits of ingroup members and portray outgroup members homogeneously and nega- 
tively. Thus, individuals with mental illness - who may act in socially deviant ways - receive stereotypes and stigmatization in automatic fashion.

When collective identity is salient, the distinction between ingroup and outgroup members as a consequence of social categorization has a profound influence on social perception, affect, cognition, and behavior. Perceptually, when people categorize other people into groups, they tend to minimize the differences between members of the same category (Tajfel \& Turner, 1979), often ignoring such differences when making decisions or forming impressions, whereas they tend to exaggerate differences between groups (e.g., "all persons with mental illness are violent" (Hogg \& Turner, 2011). This is the case when they have other characteristics, such low class affiliation or migrant status. Cognitively, people have better memory for information about ways in which ingroup members are similar to the self and outgroup members are dissimilar to the self (Wilder, 1981). Also, they remember more positive information about ingroup members (Howard \& Rothbart, 1980) and see greater connection between other members of the ingroup and the self. Lastly, they expect ingroup members to share one's attitudes and values more so than do outgroup members (Robbins \& Krueger, 2005).

These processes directly contribute to the pervasive biases that people have for ingroup members ("healthy") over outgroup members ("the mentally ill"). Emotionally, people experience more positive affect toward other members of the ingroup than they do toward members of the outgroup (Otten \& Moskowitz, 2000), and they perceive ingroup members to be more trustworthy (Voci, 2006). Thinking about people in terms of ingroup pronouns ("we" and "us") over outgroup pronouns ("they" and "them") spontaneously activates more positive associations; in fact, simply associating stimuli with "we" leads to more favorable evaluations of those stimuli than without and when paired with "they" (Perdue, Dovidio, Gurtman \& Tyler, 1990). Also, inducing people to refer to others as "we" rather as "them" or "you and I" creates more positive impressions of others (Dovidio \& Gaertner, 1993).

Importantly for issues of discrimination -such as by acting by omission-, people are more helpful toward ingroup members than toward outgroup members (Dovidio, Gaertner, Validzic, Matoka, Johnson \& Frazier, 1997). When ingroup/outgroup social categorizations are salient and personal identities are not, people tend to behave in a more greedy and less trustworthy way toward members of other groups than if they were reacting to each other as individuals (Insko et al., 2001). The act of denigrating outgroup members provides a boost to the self-esteem and behavior self-approval of observers. The universal prevalence of mental health stigma, where there are few if any sanctions against the mocking of the devalued group, suggests that there is little perceived cost to the observer who engages in stigmatization. Self-esteem enhancement is therefore another potential mechanism underlying the propensity to devalue those with mental disorders.

Moreover, stigmatization almost always exists in the context of social power 
(Link \& Phelan, 2001). Therefore, stigma takes hold when a group with social power denigrates a less powerful group (i.e., individuals with mental illness), who experience also political, economical and social disenfranchisement. Those in power tend to blame those of lower status for their own plights, as such belief systems relieve the observers of guilt for the inequalities built into the system (see "system justification" models (Lerner, 1980). Therefore, stigmatization is not simply a product of cognitive processes and biases; it exists and perpetuates itself in the context of social inequality.

Stigma acts in multiple ways, both overt and subtle. Its impact extends from delaying prompt consultation through hindering the course of treatment and interfering with rehabilitation and social inclusion (Corrigan et al., 2006; Tal et al., 2007; Corrigan, Edwards, Green, Diwan \& Penn, 2001). Consequently, stigma constitutes the hidden burden of mental disorders (Corrigan, Roe \& Tsang, 2011).

\section{THE CONTEXT}

Israel is a cultural mosaic. The majority, Israeli Jews, constitute a heterogeneous group as diverse as those from Europe-American origin with a Western medical tradition to those from Ethiopia, who hardly partakes of it. In addition, about $20 \%$ are Israelis of the Muslim faith, as well as Druze and others. All of these have their own set of mental health-related knowledge, attitudes and practices (Bilu, 1980; Daie, Witztum, Mark \& Rabinowits, 2011; Delbar, Tzadok, Mergi, Erel, Haim \& Romem, 2010; Greenberg, 1992; Krenawi, 2009; Levav, Shemesh, Grinshpoon, Aisenberg, Shershevsky \& Kohn, 2004).

Israel has a national health insurance system in which health care, including psychiatric care, is freely available (there is a very small co-payment for medicines). In addition, a relatively new legislation adopted a decade ago, "Rehabilitation of Persons with Psychiatric Disabilities in the Community", though it does not address stigma directly, it does mandate avenues of inclusion for persons with mental illness. Thus, Israel constitutes a suitable setting to examine the effect of mental health stigma under relatively favorable health service conditions.

\section{MENTAL HEALTH STIGMA IN ISRAEL: EVIDENCE FOR ITS EXISTEN- CE AND CONSEQUENCES}

A growing awareness of mental health issues and related stigma among the Israeli public and policy makers in the past two decades contributed to the promotion of a psychiatric reform (Aviram, 1996; Grinhpoon, Zilber, Lerner \& Ponizovsky, 2006; Levav \& Lachman, 2005). The reform includes three components: (1) the insurance component, which includes transferring the responsibility for the provision of psychiatric services from the state to the four national health maintenance organizations (health insurers). The latter would be responsible to establish and run a set of accessible and affordable mental health services under governmental regulation; (2) the structural component, which includes the 
process of de-hospitalization and promotion of community-based care; (3) the rehabilitation component, which entails the full implementation of a basket of psychiatric rehabilitation services. While the insurance component of the reform only recently began to be implemented, the structural and rehabilitation components are well underway.

One of the apparent results of this reform is that more Israelis with mental disorders are living in the community, and can make free use of rehabilitation services for supportive education, supported employment and housing in the community (Grinshpoon et al., 2006). This positive shift towards growing community services strengthened the community's influence on the rehabilitation process, and the recovery and social inclusion of persons with mental illness.

A question does arise as to the status of mental health stigma in Israel under this reform. Although one would hope for improvement in the acceptance of persons with mental illness and reduction in stigma, recent studies indicate that the Israeli public holds negative, stereotyping attitudes, and that there is evidence of discriminatory behaviors toward persons with mental illness (Struch et al., 2008a,b). Perhaps those individuals who have developed post-traumatic disorders (following way, terrorist attackes) may be free of them but not empirical data are available.

Struch et al. (2008a) surveyed a sample of Israeli adults aged 21 and older $(\mathrm{N}=1583)$ to examine their attitudes toward persons with mental disorders. When participants were asked which are the most common characteristics of persons with mental disorders, more than $50 \%$ replied that those persons demonstrate 'bizarre behavior, language irregularities and unkempt personal appearance'. Eighty per cent mentioned that persons with mental illness are 'unpredictable'. Moreover, while $64 \%$ agreed that persons with mental illness can work, 58\% thought that they cannot work in a normal job, such as a bank clerk. Behavioral attitudes showed a similar stigmatizing pattern with $40 \%$ reporting that they would not want a person with mental illness living in their neighborhood; $88 \%$, that they would not let a person with mental illness take their children to school; and $50 \%$, that they are willing to help a person with mental illness but are not willing to be his or her friend.

In a different study, 167 adults undergoing outpatient psychiatric treatment were surveyed for stigma-related experiences (Struch et al., 2008b). A sizeable group of service-users acknowledged that they had either feared $(31 \%)$ or experienced (57\%) rejection. Furthermore, approximately half of the respondents reported that they feared that members of their own family would not like to be with them and/or had actually been through such an experience. Regardless of actual experiences of rejection, the results showed that service users did expect some degree of rejection. This is reflected in their expectations that other people will prefer to keep a social distance from persons with mental illness. Close to one-third of the service-users reported that they had seen images or heard negative statements about people who had been hospitalized or who had received mental health care. Interestingly, the experience of stigma and rejection was not 
confined to those who had been hospitalized. It seems that the fact that a person is receiving mental health care suffices to elicit stigma, at least in the eyes of the service users themselves.

Not only individuals with psychiatric problems suffer from stigma; their families may be affected insofar as they can be considered an extension of the person with mental illness (Struch, Shereshevsky, Baidani-Auerbach, Lachman \& Sagiv, 2007). Relatives are prone to receive what Goffman (1963) termed a "courtesy stigma", a term reserved to denote the distancing and rejection that attend to individuals who are associated with members of a socially devalued category. Some family members feel responsible for their child's, parent's, sibling's or mate's mental illness, and often experience self-blame, guilt and shame (Barak \& Solomon, 2005; Struch et al., 2007) $(44,45)$.

A recent study of parents of persons with mental illness in Israel found that a considerable number (approximately 30\%) reported that people around them (their extended family, friends, neighbors, professional staff) treated them differently, as reflected in pity, blame, fear, and embarrassment. About one-fifth of the respondents reported that their neighbors had distanced themselves once they had learned of the illness, while one-quarter reported such a distance of people to whom they had been close in the past. Family members reported embarrassment about their close relative with a mental disorder, and half of them blamed themselves for having a role in the development of the illness. As a consequence, many parents $(70 \%)$ reported feeling "lonely" and "being different" as well as becoming isolated, and withdrawing from their social network (Struch et al., 2007).

An a additional study assessed the impact of schizophrenia on siblings that did not have schizophrenia with regard to objective and subjective burden, feelings and degree of closeness with sibling, social interaction, coping and sense of meaning in life. Findings were consistent and showed that siblings of persons with schizophrenia reported more intense negative feelings, elevated levels of objective and subjective burden, less closeness and more shame than the subjects in the control group (Barak \& Salomon, 2005).

Marked social distance is also perceived in the workplace and neighborhood, two settings that engender acute social exclusion with undesirable effects. Holding a job provides an important opportunity to adaptively function in society as an adult, and is considered part and parcel of the recovery process. Moreover, income helps improve the quality of life, and prevents slipping under the poverty line, a common consequence of mental illness (although persons with disability receive a disability pension by law) (Henry \& Lucca, 2004). Stigma is one of the most critical barriers to the employment of persons with mental illness. Many employers hold negative attitudes towards persons with mental illness, and as a result are unwilling to hire or provide reasonable accommodations (Scheid, 2005). Even though the majority of persons with mental disorders desire regular work, their unemployment rates are significantly higher than among those without mental disorders (Levinson \& Lerner, 2009). 
Consumers are concerned about losing Supplemental Security Income (SSI) and Social Security Disability Insurance (SSDI) benefits; they feel embarrassed about symptoms and side effects of medications; they lack the training and skills necessary for certain jobs; and they have inculcated low expectations communicated to them from support staff and others (McQuilken, Zahniser, Novak, Starks, Olmos \& Bond, 2003). Persons with disabilities work more often than others in part-time positions, lower-paying occupations, and receive less professional training. Moreover, income from employment and job security are very low compared with those without disabilities. Lastly, in old age, the employment rates of persons with disabilities are negligible compared with the rest of the population at the same ages (McQuilken, 2003).

One study Levinson \& Lerner, 2009) examined associations between having a past or current mood or anxiety disorder and being employed in the past month in a national representative sample of adults in Israel. The employment rate was lowest (35\%) among respondents with a past-month mood or anxiety disorder. Most vulnerable were those with onset before age 25 . The results indicated that employment was affected during the acute phase of a disorder, and that early onset had lasting effects in terms of job level and salary. Most of the mental health consumers in Israel with disabling disorders work in 'shelter workshops', which involves monotonous and simple tasks, and provides little income.

Although the question whether the denigrated occupational status among persons with mental illness is as result of stigma and discrimination or a consequence of impaired functioning as a result of the disorder still looms (Gal, Kaplan, Gross \& Levav, 2008), a community study (Ponizovsky, Grinshpoon, Sasson, Baidani-Auerbach, Ben \& Shershevsky, 2003) highlighted the role of stigma in limiting service users' attempt to fully reintegrate into society in Israel. In the study, the authors interviewed almost all countrywide school principals of adult education about their attitudes and knowledge. These principals are responsible for the provision of free formal education for those with mental disorders that did not complete a full cycle of schooling. The school principals were able to mention a fewer number of mental disorders in contrast to medical conditions, used as reference criteria. Their attitudes revealed an ambivalent approach to the person with a mental disorder, including those that are students. Higher level of academic education was associated with positive attitudes, while personal familiarity with a mentally disturbed person was slightly associated with more positive school-related attitudes.

Perhaps most devastating are the consequences of the internalization of negative perceptions on the part of those with mental disorders- i.e., self- stigmatization (Hinshaw \& Stier, 2008). Self-categorization theories suggest that the person's self-concept and self-esteem is partially derived from the individuals' appraisal of the his/hers group affiliation (Tajfal \& Turner, 1979). Internalized stigma plays a major role in negative changes in identity in severe mental illness. Evidence suggests that roughly one-third of people with severe mental illness show elevated internalized stigma and that it is linked to compromised outcome 
in both subjective and objective aspects of recovery.

Self-stigmatization has a profound impact on the person with mental illness, and may lead to low self-esteem, hopelessness, low self-confidence, unwillingness to seek help, treatment discontinuation, avolition, shame and social isolation (Corrigan et al., 2005; Rüsch et al., 2006; West, Yanos, Smith, Roe \& Lysaker, 2011). Internalized stigma increases avoidant coping, active social avoidance, and depressive symptoms and these relationships are mediated by the impact of internalized stigma on hope and self-esteem, leading to negative outcomes related to recovery (Yanos, Roe, Markus \& Lysaker, 2008). Link, Struening, NeeseTood, Asmussen \& Phelan (2001) in the US have discussed one of the adverse effects of stigma, namely, its negative impact on self-esteem, and warned of the complications it may produce, such as the risk of a relapse.

We are not aware of a study on self-stigma among consumers in Israel though a study by Ben-Noun (1996) who sought to characterize patients' refusal to meet a psychiatrist in a primary care clinic in Israel suggest that self-stigma is a major barrier to seeking care. Among nine types of expressions, statements, and reactions given for subjects' refusals to undergo psychiatric care, the most prevalent were: "I am afraid people would think I'm insane," "It might interfere with my social relationships and threaten my job," "I'm sufficiently strong to be able to deal with the problem myself," and "It won't help, it won't solve my problems."

Finally, the media worldwide plays a significant role in shaping and perpetuating the stigma of mental illness. In a review of the research regarding mass media's representation of mental illness by two Israel-based social scientists, the authors (Klin \& Lemish, 2008) showed the role the media plays in perpetuating misconceptions and stigma. Descriptions of mental illness and the mentally ill are distorted due to inaccuracies, exaggerations, or misinformation. The persons with disorders are presented not only as peculiar and different, but also as dangerous. Although no empirical studies on the role of mass media in mental health stigma in Israel it is possible that these negative effects are slightly attenuated due to effect of war and terror that made emotional reactions more acceptable (e.g., organizations such as Natal which provide services to victims of terror attacks that advertise their services in the radio and press and increase awareness and acceptance of emotional difficulties among the general population).

\section{SPECIFIC POPULATIONS}

Of special attention are cultural groups, such as the Israeli-Arabs and the Ultraorthodox Jews that show markedly lower formal mental health service utilization patterns (Lavav, 2009).

In the Arab world, stigma is attached to mental health services $(34,58)$. Indeed one study of Arab women's help-seeking indicates that general practitioners, rather than psychologists, psychiatrists or other mental health professionals, tend to be the preferred treatment agent. Similarly, the utilization of services may variously be interpreted, or perceive to be interpreted as reflecting, inability 
to cope on one's own, personal weakness or the socially unsanctioned need to involve those outside of the family in resolving a problem (Al-Krenawi \& Bedouin, 2000). In a sample of serviceusers from Israeli-Arab localities, a less positive perception of the benefits of mental health care was documented compared with respondents not living in Arab localities (Struch et al., 2008). Willingness to have contact with a person with a psychiatric illness was generally smaller compared with responses in non-Arab localities. Finally, there was more evidence of subtle discrimination in Arab localities than elsewhere.

The Ultra-orthodox (Haredi) Jewish community are underrepresented among new referrals to the community mental health services, tend to drop out of treatment early, and only present with severe psychopathology. Fear of stigma, contact with the irreligious world, "yihud" (union) with opposite sex therapists, suspicion of non-religious healers of the Jewish "nefesh" (soul), and seeing such a need as a sign of weakness of faith were all documented as possible deterrents for the religious person from seeking help (Greenberg, 1992). A recent survey of outpatient service-users (Struch et al., 2008) documented less positive attitudes towards seeking mental health care in ultra-Orthodox society than among the non-ultra-Orthodox Jewish population. In particular, there was less willingness to seek treatment openly. The desire to conceal the request for treatment was stronger to preserve the opportunities for arranged marriages. They were also less familiar with mental-health professionals. Social stigma against mental illness was documented to be a major barrier to seeking care. Members of the ultraOrthodox sample reported significantly higher wish to maintain a greater social distance from people with psychiatric illnesses, i.e., they are less willing to have contact (as a neighbor, colleague, boss, etc.). The perception that the "mentally ill" are violent was more prevalent in the ultra-Orthodox sample. They were fundamentally less willing to rent an apartment to a "mentally ill" person than the rest of the Jewish population.

In sum, it seems that Israeli society is similar to that of other Western countries where the general public stereotypes and stigmatizes persons with mental illness, and, as a result, may block opportunities for them to assume community roles. The ubiquitous presence of mental health stigma in Israel may be reinforced by iatrogenic factors, such as the terms used to name mental disorders and disability. A study (Levav, Shemesh, Kohn, Baidani-Auerbach, Boni, Borenstein et al., 2005) examined opinions with regard to the use the current Hebrew term for mental disorder, mahalat nefesh (disease of the soul). This term is highly dissonant with current scientific concepts whereby mental disorders are recognized as bio-psycho-social entities. Using the word soul ('nefesh') may suggest that the spiritual essence of a person is affected by the psychiatric disorder and that the dreams, hopes, love and decisions of persons with mental illness are diseased. Findings showed that while a substantial proportion of service-users rejected the current Hebrew term for mental disorder, mahalat nefesh, mental health professionals reported higher acceptance of this term compared to service-users.

Stigma and rejection often lead to adverse consequences. To cope, service- 
users apply some mechanisms that, at times, could have negative repercussions. In a survey of persons receiving care at outpatient psychiatric clinics in Israel four coping mechanism were identified: (1) Secrecy (concealment): the person with a mental disorder hides the fact that he/she is undergoing treatment, even if this exacts a marked personal toll, such as the anxiety of having this fact exposed; (2) Withdrawal: the person limits social interactions to prevent the pain of possible rejection by others; (3) Education: the person attempts to provide others with relevant information on the nature and care of mental disorders; (4) Positive distinctiveness: the person emphasizes certain favorable characteristics of the stigmatized group (e.g., "people receiving mental health care are more sensitive and care more about others"(Struch et al., 2008).

\section{CAN WE BATTLE THE BURDEN OF MENTAL HEALTH STIGMA}

The focus of psychiatric interventions has traditionally been affected by the person's psychopathology. More rarely, except for psychosocial rehabilitation programs, therapeutic efforts are geared towards providing relief from the stigma associated with the mental disorder. Yet, stigma causes suffering, interferes with all stages of care, and excludes the person from opportunities available to other members of society. Such opportunities are generally less available to persons of lower socioeconomic status, which is often the case for those with severe mental disorders (Kohn, Dohrenwend \& Mirotznik, 1998). Thus, having already been struck by illness, a person bears a double blow when struck again by lack of opportunities (Dohrenwenf, Levav, Shrout, Schwartz, Naveh \& Link, 1992).

Israeli mental health services have focused almost exclusively on one side of the equation, namely on interventions for consumers. There is an unmet need in Israel to integrate lessons learned from anti-stigma programs in other locations (e.g., the campaign "Like Minds Like Mine" in New Zealand, http://www.likeminds.govt.nz) into the rehabilitation process to overcome community barriers, and to increase the access to services, opportunities for integration and active citizenship for persons with mental illness. Such anti-stigma efforts should be multilevel spanning policy and legislation alterations in media depictions, changed attitudes and practices among mental health professionals, contact and empathy enhancement and family and individual treatments (Hinshaw, 2008).

Tal et al. (2007) suggested to apply lessons learnt from anti stigma programs elsewhere to the situation in Israel. They recommend adopting strategies to overcome stigma that will be directed to specific power groups within Israel that are key in maintaining the negative impact of mental health stigma. These groups include, employers, landlords, criminal justice professionals, policy makers, healthcare providers, the media and finally the persons with mental illness and their families. Strategies will include, legislation (housing), education and training (media and healthcare providers), and self-empowerment and political activism (consumers and their families).

For example, to tackle employers' stigma against persons with mental illness 
they recommend implementing modification and affirmative action in line with the Equal Rights for Persons with Disability Law. Modifications include with regard to equipment, job requirements, work hours, job hiring tests, training, communication of instructions for performing tasks, and work procedures. Interventions to reduce stigma and enhance work inclusion should be implemented. Such interventions can include promotion of social interactions among persons with mental illness, employers and co-workers that may help reduce fear and misconceptions about persons with mental illness. Extending the Israeli project 'structural dialogue' (Shor \& Sykes, 2002) can be one form of such interactions. In this project, persons with mental illness told their personal stories in a workplace setting. Such personal narrative can help employers and/or co-workers relate to them with less stigmatizing and more accepting behaviors. Such interactions will facilitate the contact with persons with mental illness and life experiences; enabling employers and co-workers to discover the humanity and diversity of persons with mental illness; and, in turn, persons that lead the structural dialog may be positively affected by being seen and related to in ways that validate their worth. Moreover, facilitated interactions can provide opportunities to discuss consumers' life experiences and consequently increase empathy, reduce fears, and counter stereotypes. Establishing good communication can prevent future miscommunication in the workplace.

\section{REFERENCES}

Al-Krenawi, A. (2000). Bedouin-Arab clients' use of proverbs in the therapeutic setting. International Journal for the Advancement of Counselling, 22, 91102.

Al-Krenawi, A., Graham, J.R., Al-Bedah, E.A., Kadri, H.M., \& Sehwail, M.A. (2009). Cross-national comparison of Middle Eastern university students: Help-seeking behaviors, attitudes toward helping professionals, and cultural beliefs about mental health problems. Community and Mental Health Journal, 45, 26-36.

Allport, G.W. (1954). The nature of prejudice. Reading, MA: Addison-Wesley.

Angermeyer, M. \& Matschinger, H. (2003). The stigma of mental illness: effects of labelling on public attitudes towards people with mental disorder. Acta Psychiatrica Scandinavica, 108, 304-309.

Aviram, U. (1996). Mental health services in Israel at a crossroads: promises and pitfalls of mental health services in the context of the new national health insurance. International Journal of Law \& Psychiatry, 19, 327.

Barak, D., \& Solomon, Z. (2005). In the shadow of schizophrenia: a study of siblings' perceptions. The Israel Journal of Psychiatry and Related Sciences, 42, 234.

Ben-Noun, L. (1996). Characterization of patients refusing professional psychiatric treatment in a primary care clinic. The Israel Journal of Psychiatry and Related Sciences. 
Bilu, Y. (1980). The moroccan demon in Israel: the case of "evil spirit disease". Ethos, 8, 24-39.

Brohan, E., Elgie, R., Sartorius, N., \& Thornicroft, G. (2010). Self-stigma, empowerment and perceived discrimination among people with schizophrenia in 14 European countries: The GAMIAN-Europe study. Schizophrenia Research, 122, 232-328.

Corrigan, P.W., Edwards, A.B., Green, A., Diwan, S.L., Penn, D.L. (2001). Prejudice, social distance, and familiarity with mental illness. Schizophrenia Bulletin, 27, 219-225.

Corrigan, P.W., Roe, D., \& Tsang, H.W.H. (2011). Challenging the stigma of mental illness: Lessons for therapists and advocates. Chichester, West Sussex: Wiley-Blackwell.

Corrigan, P.W. \& Watson, A.C. (2002). Understanding the impact of stigma on people with mental illness. World Psychiatry, 1, 16.

Corrigan, P.W., Watson, A.C., \& Barr, L. (2006). The self-stigma of mental illness: implications for self-esteem and self-efficacy. Journal of Social and Clinical Psychology, 25, 875-884.

Daie, N., Witztum, E., Mark. M., \& Rabinowitz, S. (2011). The belief in the transmigration of souls: Psychotherapy of a Druze patient with severe anxiety reaction. British Journal of Medical Psychology, 65, 119-30.

Delbar, V., Tzadok, L., Mergi, O., Erel, T.O., Haim, L., Romem, P. (2010). Transcultural mental health care issues of Ethiopian Immigration to Israel. Advances in Mental Health, 9, 277-87.

Dohrenwend, B.P., Levav, I., Shrout, P.E., Schwartz, S., Naveh, G., Link, B.G., et al. (1992). Socioeconomic status and psychiatric disorders: The causationselection issue. Science, 255, 946-52.

Dovidio, J.F. \& Gaertner, S.L. (1993). Stereotypes and evaluative intergroup bias. In D.M. Mackie \& D.L. Hamilton (eds). Affect, cognition, and stereotyping: Interactive processes in intergroup perception (pp. 167-93). Orlando, FL: Academic Press.

Dovidio, J., Gaertner, S.L., Validzic, A., Matoka, K., Johnson, B., \& Frazier, S. (1997). Extending the benefits of re-categorization: Evaluations, self-disclosure and helping. Journal of Experimental and Social Psychology, 33, 401420.

Gal, G., Kaplan, G., Gross, R., \& Levav, I. (2008). Status inconsistency and common mental disorders in the Israel-based world mental health survey. Social Psychiatry and Psychiatric Epidemiology, 43, 999-1003.

Goffman E. (1963). Stigma: Notes on the management of spoiled identity: Touchstone. New York.

Greenberg D. (1992). Is psychotherapy possible with unbelievers?: The care of the ultra-orthodox community. The Israel Journal of Psychiatry and Related Sciences, 28,19 .

Grinshpoon, A., Zilber, N., Lerner, Y., \& Ponizovsky, A.M. (2006). Impact of a rehabilitation legislation on the survival in the community of long-term pa- 
tients discharged from psychiatric hospitals in Israel. Social Psychiatry and Psychiatric Epidemiology, 41, 87-94.

Henry, A.D., \& Lucca, A.M. (2004). Facilitators and barriers to employment: The perspectives of people with psychiatric disabilities and employment service providers. Work, 22,169-182.

Hinshaw, S.P., Stier, A. (2008). Stigma as related to mental disorders. Annual Review of Clinical Psycholy, 4, 367-393.

Hogg, M.A., \& Turner, J.C. (2011). Intergroup behaviour, self-stereotyping and the salience of social categories. British Journal of Social Psychology, 26, 325-340.

Howard, J.W., \& Rothbart, M. (1980). Social categorization and memory for ingroup and out-group behavior. Journal of Personality and Social Psycholy, 38,301 .

Insko, C.A., Schopler, J., Gaertner, L., Wildschut, T., Kozar, R., Pinter, B., et al. (2001). Interindividual-intergroup discontinuity reduction through the anticipation of future interaction. Journal of Personality and Social Psychology, $80,95$.

Institute of Medicine. (2002). Unequal treatment: Confronting racial and ethnic disparities in health care. Washington: D.C.: The National Academies Press (cited 2011, 28 June). Available from: http://www.iom.edu/ /media/Files/ Report\%20Files/2003/Unequal-Treatment-Confronting-Racial-and-EthnicDisparities-in-Health-Care/DisparitiesAdmin8pg.pdf.

Kadri, N. \& Sartorius, N. (2005). The global fight against the stigma of schizophrenia. PLoS Medicine, 2, e136.

Klin, A. \& Lemish, D. (2008). Mental disorders stigma in the media: Review of studies on production, content, and influences. Journal of Health Communication, 13, 434-449.

Krenawi, A. (2009). The epidemiology of mental health disorders among Arabs in Israel. In: I. Levav (ed.). Psychiatric and behavioral disorders in Israel. Jerusalem: Gefen Publishing House.

Kohn, R., Dohrenwend, B.P., \& Mirotznik, J. (1998). Epidemiological Findings on Selected Psychiatric Disorders. In B.P. Dohrenwend BP (ed). Adversity, stress, and psychopathology (pp. 235-284). New York: Oxford University Press.

Lerner, M.J. (1980). The belief in a just world: A fundamental delusion. New York: Plenum Press.

Levav, I. (2009). Psychiatric and behavioral disorders in Israel. Jerusalem: Gefen Publishing House.

Levav, I., \& Lachman, M. (2005). On the way to psychiatric reform in Israel: notes for an ideological and scientific debate. The Israel Journal of Psychiatry and Related Sciences, 42, 198.

Levav, I., Shemesh, A., Grinshpoon, A., Aisenberg, E., Shershevsky, Y., \& Kohn, R. (2004). Mental health-related knowledge, attitudes and practices in two kibbutzim. Social Psychiatry and Psychiatric Epidemiology, 39, 758-764. 
Levav, I., Shemesh, A.A., Kohn, R., Baidani-Auerbach, A., Boni, O., Borenstein, .Y, et al. (2005). What is in a name? Professionals and service users' opinions of the Hebrew terms used to name psychiatric disorders and disability. The Israel Journal of Psychiatry and Related Sciences, 42, 242.

Levinson, D., \& Lerner, Y. (2009). Employment among persons with past and current mood and anxiety disorders in the israel national health survey. Psychiatric Services, 60, 655-662.

Link, B.G., Phelan, J.C. (2001). Conceptualizing stigma. Annual Review of Sociology, 363-385.

Link, B.G., Phelan, J.C., , M., Stueve, A. \& Pescosolido, B.A. (199). Public conceptions of mental illness: labels, causes, dangerousness, and social distance. American Journal of Public Health, 89, 1328-1333.

Link, B.G., Struening, E.L., Neese-Todd, S., Asmussen, S., Phelan, J.C. (2001). Stigma as a barrier to recovery: The consequences of stigma for the selfesteem of people with mental illnesses. Psychiatric Services, 52,1621-1626.

Livingston, J.D. \& Boyd, J.E. (2010). Correlates and consequences of internalized stigma for people living with mental illness: a systematic review and meta-analysis. Social Science \& Medicine, 71, 2150.

Lysaker, P.H., Tsai, J., Yanos, P., \& Roe, D. (2008). Associations of multiple domains of self-esteem with four dimensions of stigma in schizophrenia. Schizophrenia Research, 98, 194.

McQuilken, M., Zahniser, J.H., Novak, J., Starks, R.D., Olmos, A, \& Bond, G.R. (2003). The work project survey: Consumer perspectives on work. Journal of Vocational Rehabilitation, 18, 59-68.

Nordt, C., Rössler, W. \& Lauber, C. (2006). Attitudes of mental health professionals toward people with schizophrenia and major depression. Schizophria Bulletin, 32, 709-714.

Otten, S. \& Moskowitz, G.B. (2000). Evidence for implicit evaluative in-group bias: Affect-biased spontaneous trait inference in a minimal group paradigm. Journal of Experimental and Social Psychiatry, 36, 77-89.

Perdue, C.W., Dovidio, J.F., Gurtman, M.B., \& Tyler, R.B. (1990). Us and them: social categorization and the process of intergroup bias. Journal of Personality and Social Psychology, 59, 475.

Ponizovsky, A., Grinshpoon, A., Sasson, R., Baidani-Auerbach, A., Ben, E.D., Shershevsky, Y. (2003). Knowledge and attitudes about mental disorders among principals of adult education schools. The Israel Journal of Psychiatry and Related Sciences, 40, 283.

Robbins, J.M. \& Krueger, J.I. (2005). Social projection to ingroups and outgroups: A review and meta-analysis. Personality and Social Psychological Review, 9, 32-47.

Rüsch, N., Lieb, K., Bohus, M. \& Corrigan, P.W. (2006). Brief reports: selfstigma, empowerment, and perceived legitimacy of discrimination among women with mental illness. Psychiatric Services, 57, 399-402.

Scheid, T.L. (2005). Stigma as a barrier to employment: mental disability and the 
Americans with Disabilities Act. International Journal of Law \& Psychiatry, $28,670-90$.

Shor, R., \& Sykes, I.J. (2002). Introducing structured dialogue with people with mental illness into the training of social work students. Psychiatric Rehabilitation Journal, 26, 63-69.

Struch, N., Shereshevsky, Y., Baidani-Auerbach, A., Lachman, M., Sagiv N., T. Z. (2007). Stigma in the field of mental health: The attitudes, experiences, and coping mechanisms of parents of people who cope with a psychiatric illness. Jerusalem: Myers-JDC-Brookdale Institute, Contract No.: RR-468-07.

Struch, N., Shereshevsky, Y., Baidani-Auerbach, A., Lachman, M., Sagiv, N., Zehavi, T., et al. (2008a). Attitudes, Knowledge and Preferences of the Israeli Public Regarding Mental Health Services. The Israel Journal of Psychiatry and Related Sciences, 45,129.

Struch, N., Levav, I., Shereshevsky, Y., Baidani-Auerbach, A., Lachman, M., Daniel, N., et al. (2008b). Stigma experienced by persons under psychiatric care. The Israel Journal of Psychiatry and Related Sciences, 45, 210.

Tal, A., Roe, D, \& Corrigan, P.W. (2007). Mental illness stigma in the Israeli context: Deliberations and suggestions. International Journal of Social Psychiatry, 53, 547-563.

Tajfel, H. \& Turner, J.C. (1979). An integrative theory of intergroup conflict. Austin WG, Worchel S, editors. Monterey, CA: Brooks/Cole.

Turner, J.C., Hogg, M.A., Oakes, P.J. Reicher, S.D. \& Wetherell, M.S. (1987). Rediscovering the social group: A self-categorization theory: Basil Blackwell.

United Nations the Convention on the Rights of Persons with Disability. 1976 [cited 2011 June 22]; Available from: http://www.un.org/disabilities.

Voci, A. (2006). The link between identification and in group favouritism: Effects of threat to social identity and trust related emotions. British Journal of Social Psychology, 45, 265-284.

West, M.L., Yanos, P.T., Smith, S.M., Roe, D., \& Lysaker, P.H. (2011). Prevalence of internalized stigma among persons with severe mental illness. Stigma Research and Action, 1, 3 .

Wilder, D.A. (1981). Perceiving persons as a group: Categorization and intergroup relations. In D.L. Hamilton (ed.). Cognitive processes in stereotyping and intergroup behavior (pp. 213-257). Hillsdale, NJ: Erlbaum.

Yanos, P.T., Roe, D., Markus, K., Lysaker, P.H. (2008). Pathways between internalized stigma and outcomes related to recovery in schizophrenia spectrum disorders. Psychiatric Services, 59,1437. 